\title{
Seismic Imaging of Upper Crustal Structure Using Travel Times From the PASSCAL Ouachita Experiment
}

\author{
W. J. Lutter, R. L. Nowack, and L. W. Braile \\ Department of Earth and Almospheric Sciences, Purdue University, West Lafayette, Indiana
}

\begin{abstract}
A first arrival travel time inversion applied to the 1986 PASSCAL Ouachita experiment has been used to image upper crustal structure. Twenty-one shot points every $10 \mathrm{~km}$ were recorded along two $100-\mathrm{km}$-long segments with 400 seismographs on each segment. A splined velocity model parameterization allowed for the inversion of laterally inhomogeneous models but not velocity discontinuities. Over 800 travel times were used in the inversion with a variable data covariance weighting. The multiple source nature of the experiment design allowed the use of reciprocity relationships among the 21 shot points to enhance data correlation. A succession of models with velocities specified at 30,90,171, and 221 nodes were inverted for whose horizontal node spacing decreased from 100 to $12.5 \mathrm{~km}$ in the final 221 node model. Vertical node spacings of 3.0 and $1.5 \mathrm{~km}$ were used. The results of the inversions indicate changes in depth of isovelocity lines which are interpreted as Triassic fault structure based on nearby well data. The final RMS travel time residual is $0.045 \mathrm{~s}$. Resolution using first arrivals deteriorates rapidly below $9 \mathrm{~km}$ depth. Three distinct velocity gradients can be correlated with geologic units. Surface exposed Cretaceous and Jurassic sediments with velocities from 2.0 to $3.5 \mathrm{~km} / \mathrm{s}$ extend to $1.5 \mathrm{~km}$ depth. Triassic rift fill sediments, which do not outcrop, have inverted velocities ranging from 3.5 to $4.75 \mathrm{~km} / \mathrm{s}$ between depths of $1.5-3.0 \mathrm{~km}$. Paleozoic sediments are imaged by a decreased velocity gradient below a depth of $3.0 \mathrm{~km}$. Lack of resolution at depths greater than $9 \mathrm{~km}$ necessitates detailed modeling of wide-angle refiected phases to further constrain deeper crustal structure.
\end{abstract}

\section{INTRODUCTION}

Imaging crustal structure from surface seismic observations has led to the development of new techniques and experiment design. Simultaneous inversion of earthquake data for velocity structure and hypocenter have been implemented by numerous authors [Wesson, 1971; Aki and Lee, 1976; Pavlis and Booker, 1980; Thurber, 1983]. More recently, Huang et al. [1986] implemented an inversion of refraction and reflection travel times. The design of the 1986 PASSCAL Ouachita Lithospheric Seismology experiment shown in Figures 1 and 2 featured close station spacing and multiple sources to allow for imaging of the earth's crust by travel time, amplitude, and waveform techniques using reflection and refraction information. In this paper, a first arrival travel time method is described and applied to the PASSCAL Ouachita experiment.

The study area of the PASSCAL Ouachita experiment is along a major Paleozoic convergent continental margin shown in Figure 1. The experiment overlays the southern third of a COCORP reflection profile across the Ouachita Mountains and the Benton uplift in Arkansas. Four hundred seismographs were deployed in two separate profiles each $100 \mathrm{~km}$ in length. The 21 explosive sources of the experiment, shown in Figure 2, were at an average interval of $10 \mathrm{~km}$ along the profile and allowed the recording of near-vertical offset information as well as refracted and wide-angle reflected information. The experiment design, a prototype of future PASSCAL experiments, is an attempt to image crustal structure on the scale of geologic interest. The location of the experiment improves velocity control for the COCORP Ouachita experiment and the determination of deep crustal structure associated with the southern midcontinent convergent plate margin.

Copyright 1990 by the American Geophysical Union.

Paper number 89JB00706. $0147-0228 / 90 / 89 \mathrm{JB}-00706 \$ 05.00$
A first arrival travel time inversion has been used to model the PASSCAL Ouachita data set and complement other forward modeling and reflection processing based studies. Advantages of a first arrival inversion include increased velocity control, assuming that first arrivals are clearly discernible, as well as estimation of model resolution and model parameter errors. The inversion requires only correlations of first arrivals and covariance weights to produce an inverted model eliminating the trial and error process of forward modeling. The multiplicity of sources provides the necessary ray coverage to adequately image subsurface structure.

Cultural noise in the data necessitates the use of reciprocity relationships amongst the 21 shot points to facilitate travel time picks. Consequently, a covariance weighted inversion scheme has been used to weight the data according to an estimate of its uncertainty. A series of models with an increasing number of nodes are inverted for in an effort to delineate subsurface fault structures, to match first arrival travel time information and to estimate both model resolution and model parameter covariance.

\section{Travel Time INVERSion}

Until recently, seismologists have analyzed refraction profiles by the calculation of flat and dipping layer earth models. Steinhart and Meyer [1961] provide formulas for the estimation of standard error of model parameters for such models. Advances in theoretical techniques and their computer implementation have led to analysis based on accurate forward modeling of refracted travel time data. Many authors have pointed out the nonuniqueness of such modeling and the need for their refinement by the utilization of amplitude information [e.g., Healy, 1963; Fuchs, 1970; Braile and Smith, 1975 and Banda et al., 1982]. For all the good points of forward modeling, there are also drawbacks. The time and manpower needed to coordinate modeling of multiple source large experiments are considerable. After modeling, error bounds on model parameters can only be estimated by using a Monte Carlo approach. Different model parameterizations and individual 


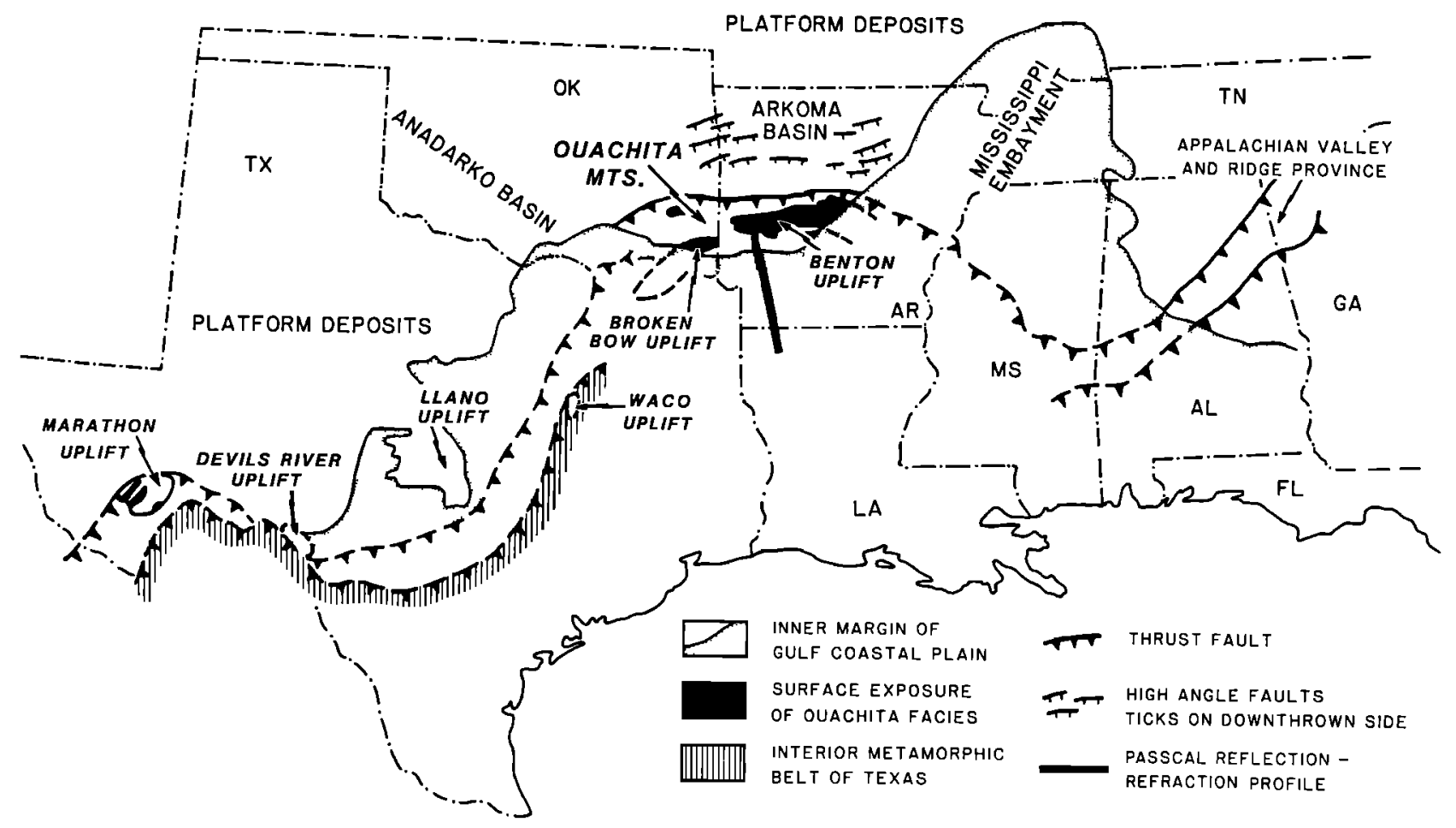

Fig. 1. Tectonic setting of the PASSCAL Ouachita lithospheric seismic experiment. Figure from Plappert [1987].

researcher methodology create an a priori subjectivity inherent in forward modeling [Mooney and Prodehl, 1984]. It is useful to complement forward modeling with less subjective methods of analysis which also allow the systematic estimation of model error. Aki et al. [1976] were among the first to implement a three-dimensional travel time inversion using teleseismic data which was both objective and allowed calculation of resolution and model error.

A variety of velocity model parameterizations have been used to invert travel time data. Aki and Lee [1976] implemented block models with constant velocities in each block. Other parameterizations include analytical equations [Wesson, 1971], polynomial coefficients [Firbas, 1981], regions of constant velocity gradient [Whittal and Clowes, 1979], and a regular grid system with velocities specified at each node point [Thurber, 1983]. Researchers who have applied these methods to refraction data from explosive sources include Ankeny et al. [1986], Benz and Smith [1984], Elbring [1984], Huang et al. [1986], Kanasewich and Chiv [1985], and Spence et al. [1985].

The method of parameterization used in this paper is a bicubic spline interpolation of an arbitrary rectangular grid of velocity nodes. This parameterization, standard on forward model ray codes based on the ray theoretical development of Cerveny et al. [1977], facilitates the calculation of amplitudes as well as amplitude derivatives [see Nowack and Lutter, 1988a]. As implemented in this paper, this parameterization does not include discontinuities in the velocity model. The addition of interfaces would allow the use of additional reflected information [see Bishop et al., 1985; Nowack and Lyslo, 1990; Lutter and Nowack, this issue].

Travel time inversion is a nonlinear problem which can be linearized to obtain an iterative solution of the equation

$$
A m=d
$$

where $A$ is the partial derivative matrix, $m$ is the model parameter correction vector, and $d$ is the data residual vector. Partial derivatives of travel time with respect to velocity are calculated by velocity node perturbation using Fermat's principle:

$$
\frac{\partial T}{\partial V_{N}}=-\int_{s_{0}}^{s} v^{-2}(x) \frac{\partial v}{\partial V_{N}} d s
$$

where $v$ is the velocity of the unperturbed model along the ray, $\partial v / \partial V_{N}$ is the change in the velocity along the ray due to a perturbation of a velocity at a model node point, and $d s$ is the arclength along the unperturbed ray. The integral expression in (2) is evaluated numerically from $s_{0}$ to $s$, the source and receiver positions for each ray. Using a single raytrace, the partial derivatives for $V_{N}$, the velocities at $n$ model node points, can be calculated from (2). The linearized system can then be written

$$
\frac{\partial T_{i}}{\partial V_{j}} \delta V_{j}=\delta T_{i}
$$

for $i=1, m$ rays, and $j=1, n$ velocity nodes. Source and receiver site corrections could be included but have not been used in this study.

The partial derivative matrix is sparse, and thus a sparse matrix least squares method has been used for the inversion [Paige and Saunders, 1982]. The Paige-Saunders algorithm is a conjugate-gradient method requiring in general $n$ evaluations of the gradient of the function to reach the minimum of an $n$ dimensional quadratic form. Repeated cycles converge quadratically for nonquadratic forms. The method allows the introduction of damping and compares favorably with other methods for solving large tomographic systems [Nolet, 1985]. 


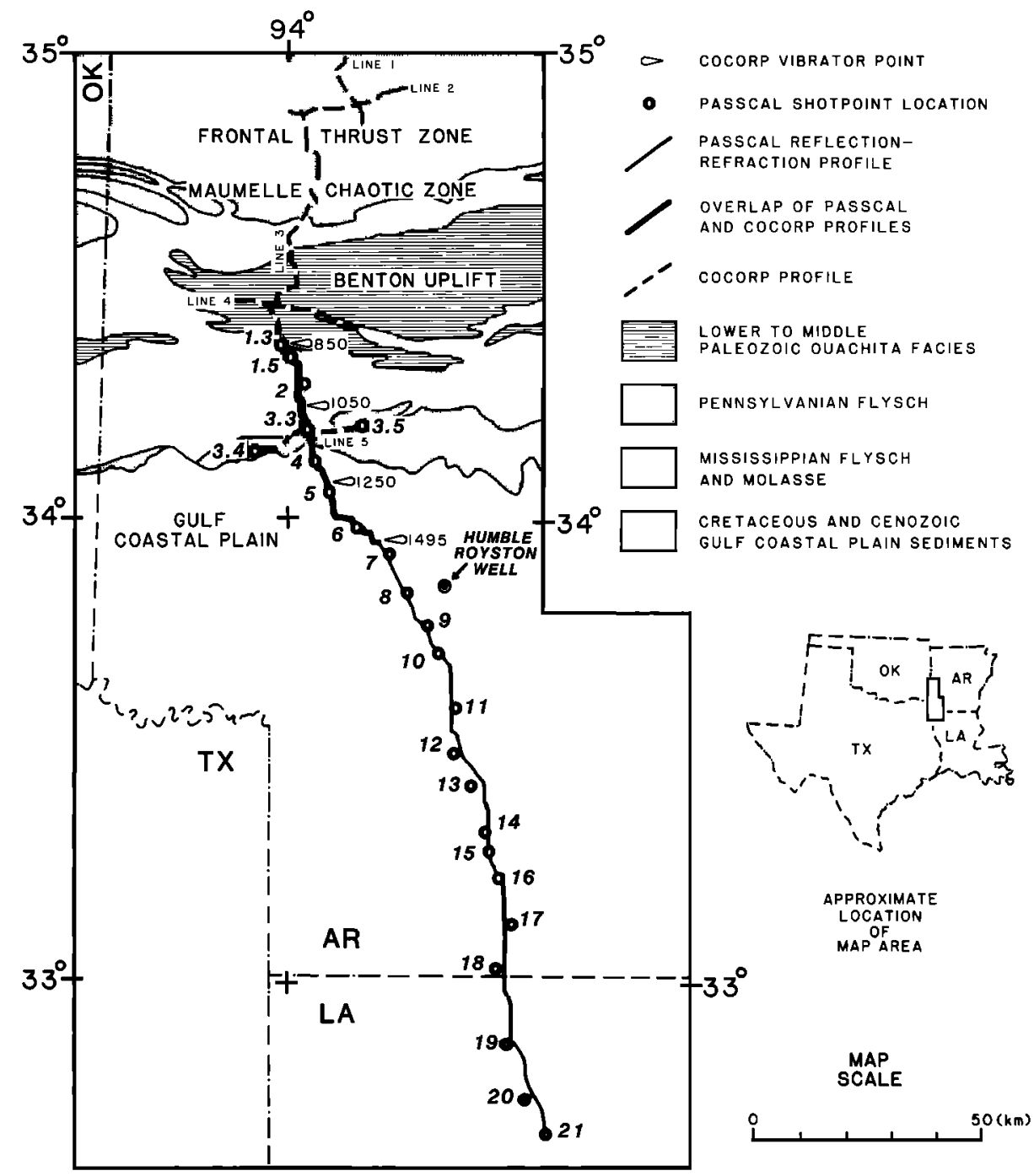

Fig. 2. Location map of the PASSCAL Ouachita experiment which overlays the southem third of the COCORP Ouachita Profile. The 21 PASSCAL shot points are indicated by numbered circles. Figure from Plappert [1987].

The introduction of damping allows the solution of the damped least squares equation

$$
\left[\begin{array}{l}
A \\
\varepsilon I
\end{array}\right][m]=\left[\begin{array}{l}
d \\
0
\end{array}\right]
$$

In the normal equation form, the solution can be written

$$
m=\left(A^{T} A+\varepsilon^{2} I\right)^{-1} A^{T} d
$$

For the maximum likelihood or stochastic inverse, the solution takes the form $m=A_{g}{ }^{-1} d$, where

$$
A_{g}^{-1}=\left(A^{T} C_{D}^{-1} A+C_{M}^{-1}\right)^{-1} A^{T} C_{D}^{-1}
$$

where $C_{M}$ is the a priori model covariance and $C_{D}$ is the estimated data covariance.

Assuming $C_{D}=\sigma_{D}^{2} I$ and $C_{M}=\sigma_{M}^{2} I$, the stochastic inverse reduces to (5) with $\varepsilon^{2}$ given by [see Aki and Richards, 1980]

$$
\varepsilon^{2}=\frac{\sigma_{d}^{2}}{\sigma_{m}^{2}}
$$

The damping parameter $\varepsilon$ must be chosen to minimize the trade-off curve between spread of resolution and size of covariance [Menke, 1984]. If the model parameterization is continuous (infinitely fine discretization) the trade-off curves are monotonic and asymptotic with respect to resolution and variance. However, sufficiently fine discretization maintains these trade-off curve characteristics [Menke, 1984]. Jordan [1972] has shown that the stochastic inverse lies on the optimal point of the trade-off curve [Aki and Richards, 1980].

The iteration of the linearized inversion is continued until a stopping criteria based on an $F$ test is met [Menke, 1984]. The ratio used in the $F$ test is a function of relative error between the different observations, the number of observations, and the number of model parameters for two distinct models. The significance of improved model fit resulting from each inversion iteration is tested at a $5 \%$ significance level.

Model resolution and standard deviation of model parameters are calculated separately from the Paige-Saunders algorithm. The resolution matrix filters the true earth model parameters to give the estimated model parameters $m=R m_{t r m}$ where

$$
R=A_{g}^{-1} A=\left(A^{T} C_{D}^{-1} A+C_{M}^{-1}\right)^{-1} A^{T} C_{D}^{-1} A
$$

The a posteriori model covariance is usually expressed as 


$$
C_{M}^{\prime}=\left(A_{g}^{-1}\right) C_{D}\left(A_{g}^{-1}\right)^{T}
$$

When $\varepsilon \neq 0, R$ may be factored out to give $C_{M}^{\prime}=R(I-R) C_{M}$. Tarantola [1987] has derived the following modified form for the a posteriori covariance:

$$
C_{M}^{\prime}=\left(A^{T} C_{D}^{-1} A+C_{M}^{-1}\right)^{-1}
$$

This leads to the formula used in this paper to calculate a posteriori covariance from the resolution matrix

$$
C^{\prime}{ }_{M}=(I-R) C_{M}
$$

See the appendix for more details conceming the a posteriori covariance.

This method of inversion is computationally efficient incorporating the Paige-Saunders algorithm with a calculation of partial derivatives which requires a single raytrace per iteration. It is particularly advantageous in simultaneously inverting a large volume of data such as the PASSCAL Ouachita experiment.

\section{TeCtonic BaCKground}

The PASSCAL Ouachita Lithospheric Seismology experiment was conducted in southwestern Arkansas and northeastern Louisiana (Figure 1) to help delineate the tectonic evolution of the Ouachita Orogenic belt. Four major phases of tectonic activity are associated with the Ouachita orogenic system. An Eocambrian continental breakup resulted in a passive margin and the opening of the Ouachita ocean basin. The closing of the ocean basin due to subduction began in the Devonian or Mississippian. This climaxed in the Pennsylvanian with the Ouachita orogenic event. Finally, rifting occurred in the Triassic associated with the opening of the Gulf of Mexico [Houselonecht and Kacena, 1983; Kruger and Keller, 1986].

In the Eocambrian, a major episode of rifting resulted in the opening of the Ouachita ocean basin and the development of rift basins along the southern margin of North America [Thomas, 1977]. The southern margin evolved into a passive Atlantictype margin which persisted throughout the early and middle Paleozoic [Houseknecht and Kacena, 1983]. The gravity signature of the margin, according to Kruger and Keller [1986], is delineated by the interior zone gravity maximum, positioned south of the Ouachita system, whose center crosses the PASSCAL profile approximately at shot point 6 (see Figure 2). Lillie [1985] interpreted a wedge-shaped reflection sequence observed on the Ouachita COCORP reflection profile as separating continental and oceanic crust.

A variety of tectonic models have been proposed to explain the Ouachita orogenic belt. Keller and Cebull [1973] proposed an Andean-type subduction to the north. Morris [1974] suggested fringing island arcs subducting to the north. In recent years, a number of models have been proposed involving an Atlantic-type continental margin subducting to the south beneath either an island arc system, a microcontinent, or a larger continental mass [Walper, 1977; Nelson et al., 1982; Lillie et al., 1983].

The Ouachita orogenic belt extends from the Mississippi to northem Mexico. A series of basement highs are positioned along the orogenic belt including the Benton uplift located along the COCORP reflection profile north of the PASSCAL Ouachita profile. Lillie et al. [1983] interpret the Benton uplift to have a antiformal seismic expression at depth. Lillie [1985] interprets a volcanic wedge on the southern flank of the antiform as marking the oceanic continental crustal boundary. The wedge and antiform are interpreted to be buried beneath overthrusted
Ouachita facies rocks. Lillie et al. [1983] interpret imbricate thrust faulting to have occurred south of the Benton uplift where Paleozoic sediments are at least $14 \mathrm{~km}$ thick.

Rifting in the Triassic as the Gulf of Mexico began to reopen is documented by the presence of Triassic red beds deposited in grabens. Elongated gravity minima gulfward of the interior zone gravity maximum whose center crosses the PASSCAL profile at shot point 10 are the signature of the grabens according to Kruger and Keller [1986].

The tectonic intricateness and COCORP Ouachita profile interpretations have motivated the placement of the PASSCAL Ouachita experiment profile to overlap the southerm one third of the COCORP profile. This allows for improved velocity control and imaging of deeper crustal structures associated with the COCORP interpretations.

\section{PASSCAL OUACHITA EXPERIMENT}

The PASSCAL Ouachita experiment was a prototype experiment whose design featured sufficient sensors, 400 seismic group recorders on loan from Amoco Production Company, and station spacings of $0.25 \mathrm{~km}$ to avoid spatial aliasing. Two 100-km-long segments were deployed. Large shots with over $2000 \mathrm{lbs}$ of explosives were positioned every 50 $\mathrm{km}$ (shot points $1.5,7,11,16$, and 21). However, only profiles 1.5 and 16 recorded usable energy along the entire $200-\mathrm{km}$ length of the experiment. Smaller shots were positioned every $10 \mathrm{~km}$ to record near-vertical incidence reflected energy, wideangle reflected energy and refracted energy.

The clarity of first arrivals from shot profiles over the northem $100 \mathrm{~km}$ of the experiment is indicated by profile 5 displayed in Figure 3. Located $34.8 \mathrm{~km}$ from the northern end of the experiment, profile 5 has curved first arrival branches with several prominent arcuate travel time delays. Apparent velocities range from 3.5 to $5.7 \mathrm{~km} / \mathrm{s}$ for distances out to $30 \mathrm{~km}$. Profile 5 north extending to $35 \mathrm{~km}$ is smoothly curving with apparent velocities of $4.4 \mathrm{~km} / \mathrm{s}(\mathrm{bb})$ and $5.7 \mathrm{~km} / \mathrm{s}(\mathrm{cc})$. Labeled correlations (aa), (bb), and (cc) on profile 5 south, $65 \mathrm{~km}$ in length, have apparent velocities of $2.8,4.6$, and $5.3 \mathrm{~km} / \mathrm{s}$. Correlations (dd) and (ee) corresponding to a travel time delay between 20 and $30 \mathrm{~km}$ have apparent velocities of 4.7 and 5.7 $\mathrm{km} / \mathrm{s}$. The $0.7 \mathrm{~s}$ travel time delay between 30 and $50 \mathrm{~km}$ has an average apparent velocity of $5.0 \mathrm{~km} / \mathrm{s}$ and is denoted (ff) before increasing to an apparent velocity of $5.8 \mathrm{~km} / \mathrm{s}(\mathrm{gg})$.

Travel time delays on profile 5 south at 20 and $30 \mathrm{~km}$ out to $60 \mathrm{~km}$ suggest sediments dipping to the south with either lateral velocity variations or fault structure. The general trend of the $0.7 \mathrm{~s}$ travel time delay is observed on profiles 1 south, 4 south, and 6 south at the same absolute position. It is roughly coincident with a gravity minimum gulfward of the interior zone gravity maximum which is associated with Triassic rifting [Kruger and Keller, 1986]. The smaller travel time delays between 20 and $30 \mathrm{~km}$ are seen most prominently on profiles 5 south and 4 south.

The discussion of profile 5 is illustrative but not inclusive of shallow crustal features of the PASSCAL Ouachita data set. In contrast to forward modeling where features must be correlated from profile to profile to model arrivals, one need only pick first arrivals to compute a model based on travel time inversion.

\section{Application of Inversion to the Passcal Travel Time Data}

A 10-km interval between shot points allowed the use of reciprocity relationships between profiles to enhance the 


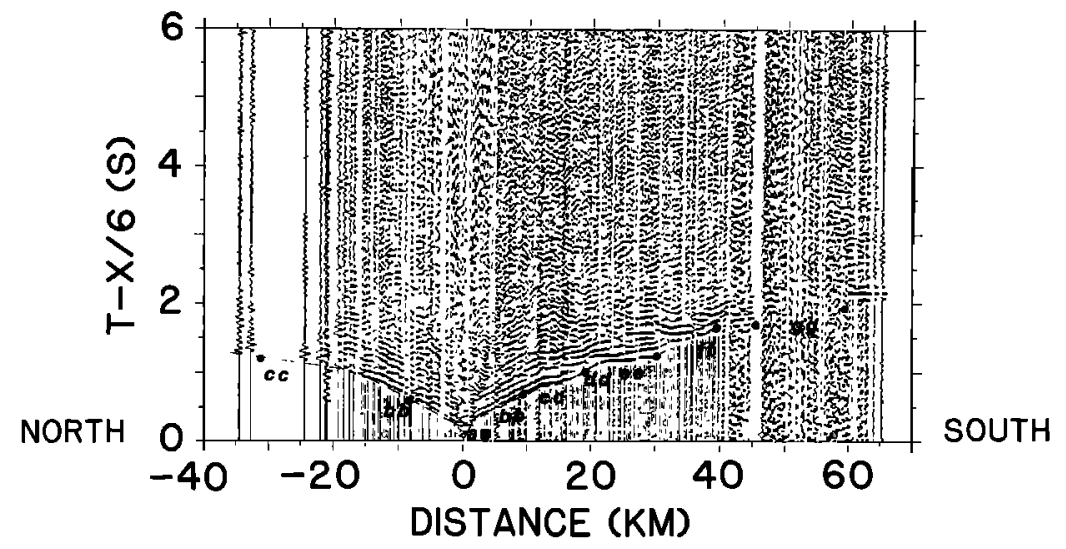

Fig. 3. Split profile of shot point 5. Correlations are described in text. Solid dots are reciprocity points with other shot points.

identification of travel time correlations associated with apparent velocities greater than $5.5 \mathrm{~km} / \mathrm{s}$. First arrivals were ambiguous past $40 \mathrm{~km}$ from the source on many profiles. Although for low noise data, reciprocity is redundant, this redundancy is a valuable tool to ensure consistent identification of first arrivals in regions with low signal to noise ratio. The extension of reliable correlations into regions of low signal to noise ratio nearly doubles the invertible data and improves the imaging of deeper crustal structure.

The inclusion of data from regions of low signal to noise ratio necessitated the use of weighting in the inversion scheme. First arrival travel times were weighted by assigned data standard deviations. Clear first arrivals were assigned a data standard deviation of $0.025 \mathrm{~s}$ (equal to a quarter of the dominant period). Correlatable energy partially obscured by cultural noise which were in agreement with reciprocity relationships were assigned a standard deviation of $0.037 \mathrm{~s}$. Correlations based primarily on reciprocity were given a data standard deviation of $0.05 \mathrm{~s}$. This implies that the probability of the true pick being within a $0.2-\mathrm{s}$ window (two standard deviations) is $98 \%$. The use of variable data covariance weighting in the inversion based on these values lowers resolution values by approximately 5 10\%. A scaling was then applied in order to use a single damping parameter $\varepsilon$ [see Ellsworth and Koyanagi, 1977].

A damping value of $\varepsilon=0.5$ used in all inversion runs except model $30 \quad(\varepsilon=1.0)$ was based on several considerations. Ideally, an $\varepsilon$ value is chosen to minimize the trade-off curve between spread of resolution and size of covariance. However, the knee of the trade-off curve provides a range of possible epsilon values. Empirically, an $\varepsilon$ was chosen as low as possible to improve statistical resolution of model parameterization as measured by the diagonal elements of the resolution matrix while still damping out unwanted oscillations of model parameters. The stochastic interpretation of $\varepsilon$ comes from equation (7) as the ratio of normalized data to model variance. A normalized data error of $0.025 \mathrm{~s}$ and an a priori model error of $0.05 \mathrm{~km} / \mathrm{s}$ results in the $\varepsilon$ value of 0.5 .

First arrival times were sampled for all 21 shots with reciprocity points embedded within the set of picks. A onedimensional spline routine [Cline, 1974] was used to coordinate the set of picks with forward model travel time data at 2- and 4-km intervals. Figure 4 illustrates the travel times and raypaths used in the inversion. The top panel shows approximately 400 of the travel time data points. It also indicates that the velocity

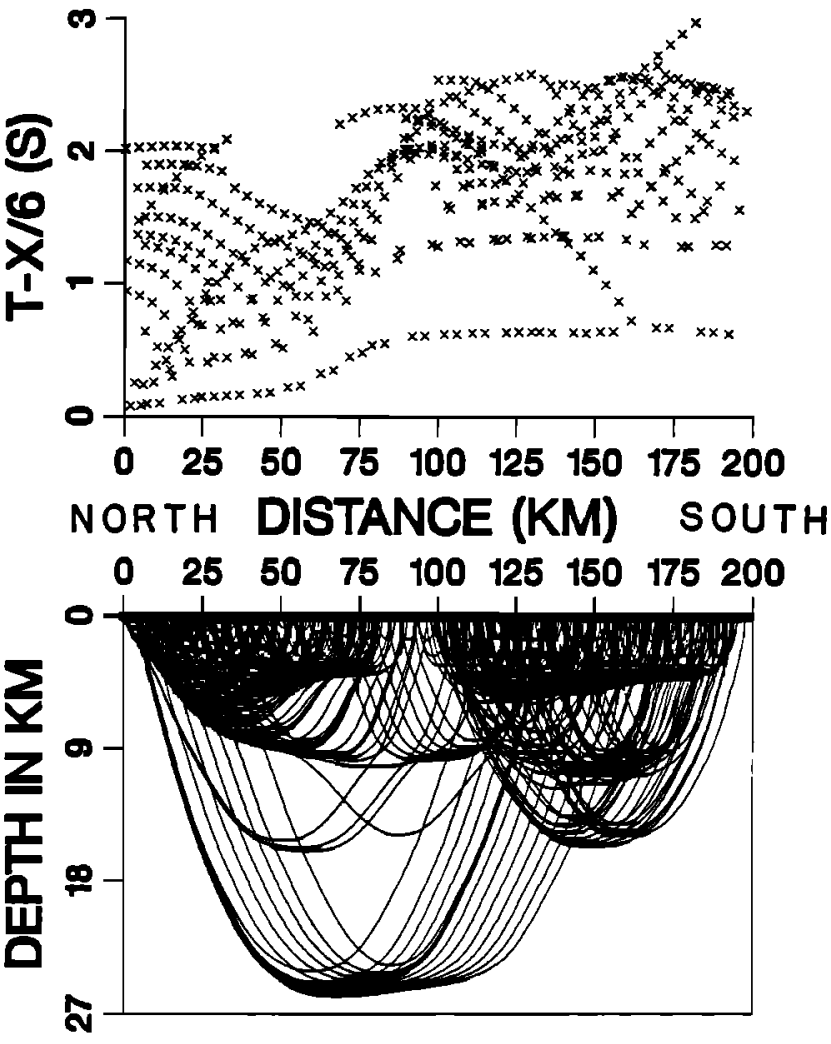

Fig. 4. Travel times and raypaths for starting model displayed in Figure 5. Top panel shows over $\mathbf{4 0 0}$ travel times used in the inversion. Bottom panel illustrates ray coverage.

model will be slower to the south for the near surface. The ray coverage displayed in the bottom panel illustrates that model resolution and ray hit count will be best for portions of the model shallower than $9 \mathrm{~km}$.

Two sets of inversions were run. A starting model with a homogeneous velocity gradient with velocities of $4,5,6$, and $6.5 \mathrm{~km} / \mathrm{s}$ at $0,4,8$, and $16 \mathrm{~km}$ was used for the first set of inversions. Clear first arrivals which were correlatable without invoking reciprocity were inverted in a series of models which sequentially halved either vertical or horizontal node spacing. No velocity discontinuities were allowed in these models due to 
the splined velocity parameterization. One of these models shown in Figure 5 was then used as a starting model for the second set of inversions which included data covariance weighting and the extended data set of first arrivals. Contours are isovelocity lines at $0.5 \mathrm{~km} / \mathrm{s}$ intervals. Velocities were specified on a 30-node rectangular grid of points. Horizontal nodes were positioned at 0,100 , and $200 \mathrm{~km}$. Vertical nodes were positioned every $3 \mathrm{~km}$ to a depth of $27 \mathrm{~km}$. The upper 6 $\mathrm{km}$ kept from the original inversion model are flat layered between 100 and $200 \mathrm{~km}$ and dip to the south between 0 and $100 \mathrm{~km}$. At depths greater than $6 \mathrm{~km}$ a homogeneous velocity gradient with velocities of $6.1,6.6$, and $7.0 \mathrm{~km} / \mathrm{s}$ at depths of 9 , 12 , and $24 \mathrm{~km}$, respectively, was initially used.

A series of inversions were then run where the starting model for one inversion was the final model of the previous inversion. For example, the final model for the 30 -node inversion just described was used as the starting model for a 90-node inversion with horizontal nodes every $25 \mathrm{~km}$ and vertical nodes maintained at $3 \mathrm{~km}$ in a rectangular grid. Node intervals were then halved vertically and horizontally in order to improve spatial resolution of model structure. Models were smoothed and splined to build a larger node model from a smaller node model. Vertical node spacing was halved to $1.5 \mathrm{~km}$ to generate a 171-node model. A further reduction of horizontal node spacing to $12.5 \mathrm{~km}$ was made in a 221 -node model. Depths below $18 \mathrm{~km}$ were fixed to the respective velocity values of the 171-node model. Over 800 data points at 2 -km intervals were used in the final inversion. The progression of model features, travel time fit, and resolution will be discussed for the 90-node and 221-node inversion.

In general, both models have similar features, with model 221 providing better near-surface detail due to the doubling of travel time data points used in the inversion and to the increased spatial resolution caused by the model parameterization. These features take the form of flat or dipping isovelocity lines associated with high-velocity gradients and changes in the depth of isovelocity lines over small horizontal distances associated with lower-velocity gradients which are perhaps indicative of fault structures. Anticlinal and synclinal isovelocity features are evident in these models. Figures $6 a$ and 8 display isovelocity lines for models 90 and 221 which have been slightly smoothed prior to contouring. Coefficients of 0.8 and 0.05 were used to weigh individual nodes and the four neighboring nodes respectively in order to enhance the geologic appearance of contour lines. Figure 7 displays triplets of numbers associated

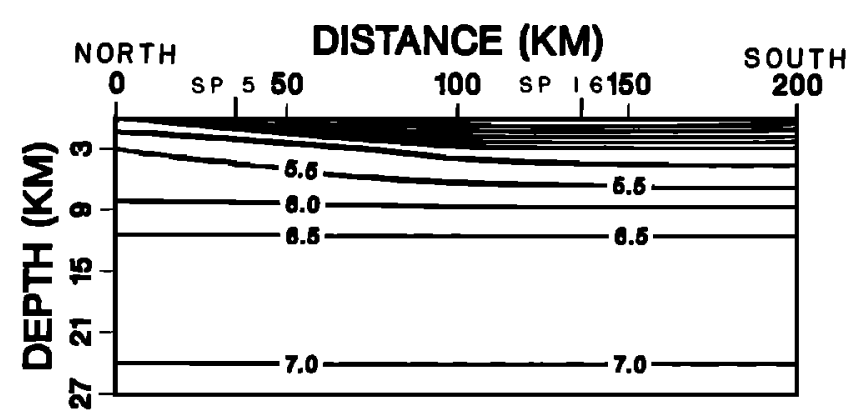

Fig. 5. Starting model for a set of inversions including covariance weighting and extended data set. Contours are isovelocity lines at .5 $\mathrm{km} / \mathrm{s}$ intervals. Model is fiat layered to south $(100-200 \mathrm{~km})$ and dips to the south between 0 and $100 \mathrm{~km}$. The COCORP reflection profile overlaps between 0 and $45 \mathrm{~km}$ on the PASSCAL profiles.

\section{MODEL 90}
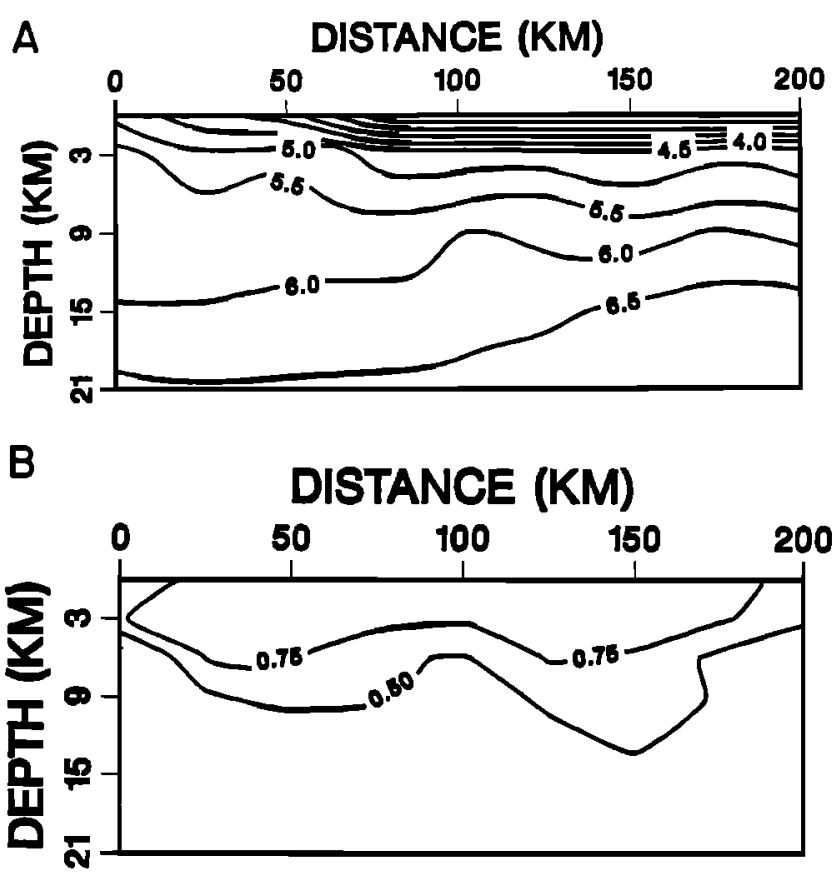

Fig. 6. (a) Contour diagram of isovelocity lines for model 90 at 0.5 $\mathrm{km} / \mathrm{s}$ intervals. (b) Diagonal elements of the resolution matrix are contoured for model 90.

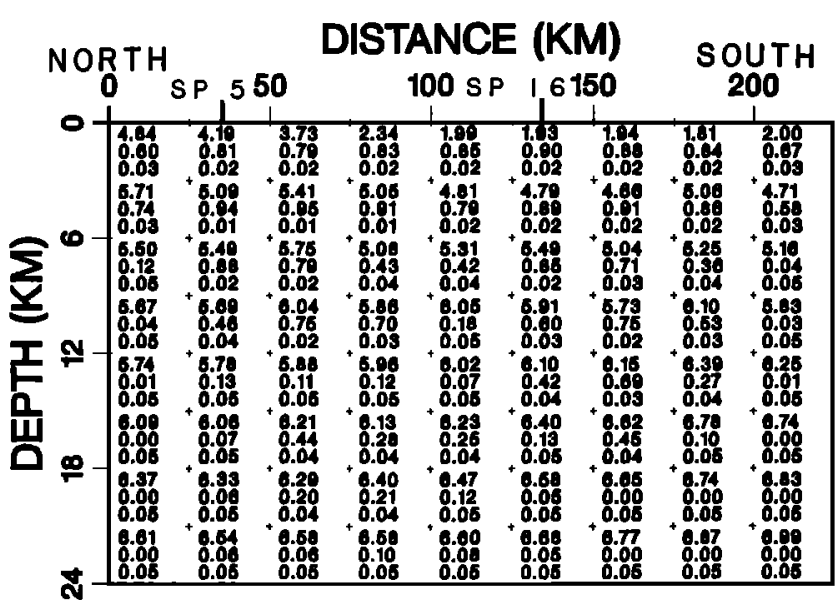

Fig. 7. Plot of velocity, resolution, and standard error estimate for nodes between 0 and $15 \mathrm{~km}$ depth for model 90 . Velocity is top number, resolution is middle number, and upper bound of standard deviation of model parameter is bottom number for each triplet.

with each velocity node (unsmoothed) shallower than $18 \mathrm{~km}$ for model 90. The triplet of numbers are velocity (top), resolution (middle), and the standard deviation of the velocity (bottom).

The most noticeable feature of model 90 are the flat isovelocity lines between 100 and $200 \mathrm{~km}$ and southerly dipping isovelocity lines between 0 and $100 \mathrm{~km}$ at depths of $0-3 \mathrm{~km}$. These features are associated with a high-velocity gradient of approximately $0.9 \mathrm{~km} / \mathrm{s} / \mathrm{km}$. Between 0 and $50 \mathrm{~km}$ horizontally, there is a lower velocity gradient of approximately 0.25 $\mathrm{km} / \mathbf{s} / \mathbf{k m}$. 
There are three prominent regions in model 90 where rapid changes in depth of isovelocity lines occur. Isovelocity lines with velocities near $5.5 \mathrm{~km} / \mathrm{s}$ increase in depth from 3 to $6 \mathrm{~km}$ between 50 and $75 \mathrm{~km}$. This change in depth is progressively smaller for velocities up to $5.9 \mathrm{~km} / \mathrm{s}$ at a $9-\mathrm{km}$ depth and constitutes a steeply dipping southem flank of a broader anticlinal feature in velocity. By $9 \mathrm{~km}$ depth, the isovelocity lines have flattened. Below $9 \mathrm{~km}$, the velocity model is faster to the south as evidenced by the 6.0 and $6.5 \mathrm{~km} / \mathrm{s}$ isovelocity lines in Figures $6 a$ and 8 . However, resolution deteriorates rapidly below $9 \mathrm{~km}$ depth.

A broad synclinal feature evident on isovelocity line contours with velocities of $5.0,5.5$, and $6.0 \mathrm{~km} / \mathrm{s}$ is positioned horizontally between 125 and $175 \mathrm{~km}$ and at depths from 3 to $12 \mathrm{~km}$. This feature blends into the steeply dipping anticlinal shaped contours centered at $50 \mathrm{~km}$.

Major features of model 221, displayed in Figure 8 correlate with features described for model 90 . The anticlinal structure centered between 25 and $75 \mathrm{~km}$ is evident at depths from 3 to $15 \mathrm{~km}$. It is noticeable on isovelocity contours between 5.0 and $6.0 \mathrm{~km} / \mathrm{s}$. The top of the anticline at $3 \mathrm{~km}$ grades into a region of horizontal isovelocity lines between 25 and $63 \mathrm{~km}$. Between 63 and $75 \mathrm{~km}$ contours near $4.5 \mathrm{~km} / \mathrm{s}$ change depth between 1.5 and $3 \mathrm{~km}$. Above $9 \mathrm{~km}$ the model is flat layered between 75 and $125 \mathrm{~km}$. A synclinal structure is evident between 125 and $175 \mathrm{~km}$ at depths of $3-12 \mathrm{~km}$. South of the anticline between depths of $9-16 \mathrm{~km}$, contour lines shallow to the south for velocities in the range of $5.5-6.5 \mathrm{~km} / \mathrm{s}$.

Model 221 is vertically stratified, and three regions with different velocity gradients are evident. Between 0 and $1.5 \mathrm{~km}$ vertically and 100 and $200 \mathrm{~km}$ horizontally, velocities range from roughly 1.9 to $3.6 \mathrm{~km} / \mathrm{s}$. This region of the model has the highest velocity gradient of approximately $1.0 \mathrm{~km} / \mathrm{s} / \mathrm{km}$. The region between 100 and $200 \mathrm{~km}$ horizontally and 1.5 and 3.0 $\mathrm{km}$ vertically has a gradient of $.83 \mathrm{~km} / \mathrm{s} / \mathrm{km}$ with velocities increasing from 3.6 to $4.75 \mathrm{~km} / \mathrm{s}$. Below $3 \mathrm{~km}$ the velocity model has a significantly lower gradient of less than 0.3 $\mathrm{km} / \mathrm{s} / \mathrm{km}$.

\section{Discussion}

The usual measure of goodness of fit of a model is the match or mismatch between observed and predicted data. This goodness of fit will be discussed with respect to a root mean square travel time residual displayed in Figure 9 and the travel

\section{MODEL 221}

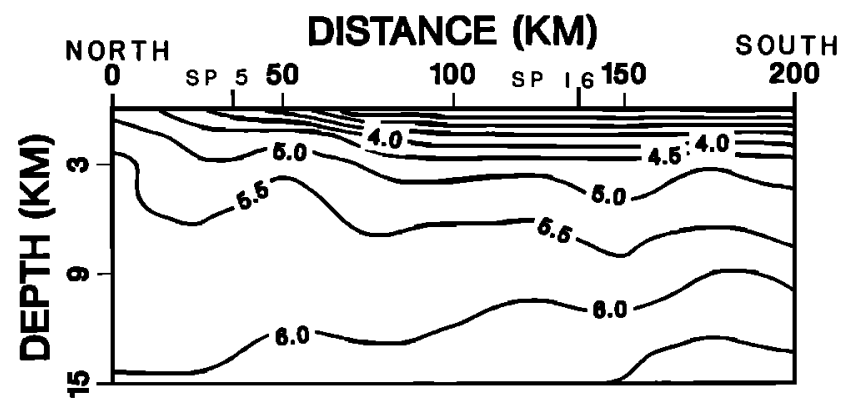

Fig. 8. Contour diagram of isovelocity lines for model 221 with contour intervals of $0.5 \mathrm{~km} / \mathrm{s}$.

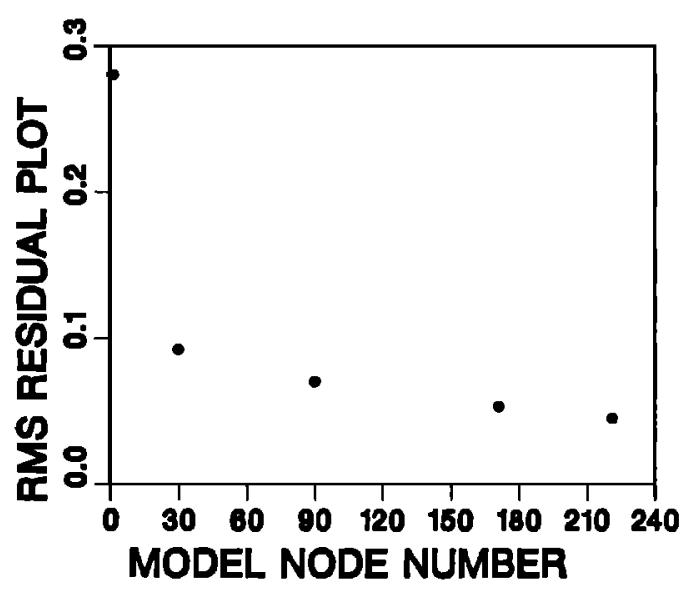

Fig. 9. Root mean square travel time residual plotted versus Lotal node number for each inversion model. The starting 30 node model has a RMS residual of 0.28 .

time fit of models 90 and 221 to profiles 5 and 16 shown in Figure 10. In addition, the significance of the improved data fit resulting from an increased number of nodes can be examined by an $F$ test.

The starting 30-node model for the covariance weighted inversion has an RMS travel time residual of $0.28 \mathrm{~s}$, largely due to mismatch of deeper model structures. The final 30-node inversion after three iterations has reduced the residual to 0.09 s. Interpolating a final model to construct a starting model with a greater number of nodes usually slightly increases the RMS residual. For instance, the 90-node starting model has a RMS residual of $0.104 \mathrm{~s}$ which is increased 0.014 from the 30-node

A
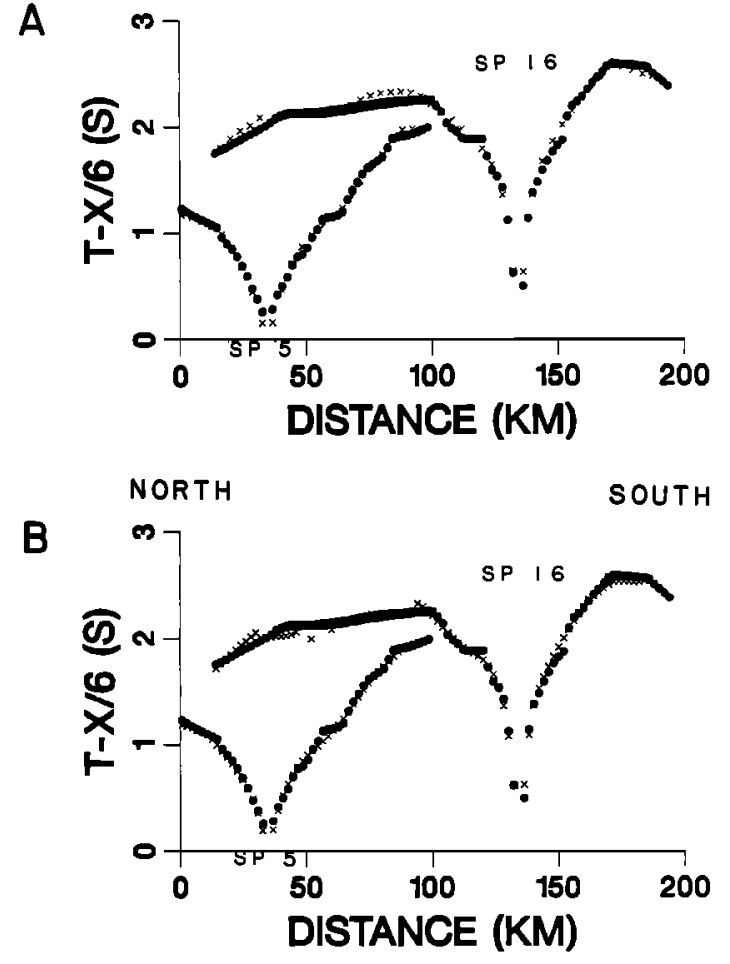

Fig. 10. Travel time fit to profiles 5 and 16 for (a) model 90 and (b) model 221. 
final model. After two iterations the RMS residual is reduced to $0.067 \mathrm{~s}$. This is a $75 \%$ reduction of the original RMS error. Two iterations of a 171-node model and two iteration of a 221node model further reduce this to $0.045 \mathrm{~s}$, an $84 \%$ reduction of the original RMS error. At this point, we are within the range of the original estimated data standard error.

The general trend of travel times is matched by models 90 and 221 as displayed in Figures $10 a$ and $10 b$. Model 221 is an improved fit due to decreased horizontal spacing between velocity nodes. The travel time picks from the inversion models have changes in slope in approximately the same positions as correlations described for profile 5 (Figure 3). Several travel time delays may be related to model features. Travel time delays seen in Figures 3 and $10 a$ on profile 5 south are associated with low velocity flanks of the anticline pattern of isovelocity lines centered at $50 \mathrm{~km}$. The large $0.7-\mathrm{s}$ delay is possibly related to a fault structure between 67.5 and $75 \mathrm{~km}$ at depths of 1.5-3 km and also at greater depths to the southem flank of the anticlinal feature. The smaller travel time delay on Figure 3, correlations dd and ee between 20 and $30 \mathrm{~km}$, is correlative with the northern flank of the anticlinal feature. The anticlinal shape of isovelocity lines thus appears to be a necessary feature of the model and not an oscillation due to low damping. The travel time signature of the syncline is more subtle: at $20 \mathrm{~km}$ from shot point 16 , profile 16 south is $0.25 \mathrm{~s}$ slower than profile 16 north. These models show the improved travel time fit resulting from an increased number of model parameters in the inversion.

Although increasing the number of model parameters in the inversion results in an improved fit to the data, the question arises as to how significant this improvement is. The significance of the improved data fit resulting from an increased number of model parameters can be examined by an $F$ test. The significance of improved data fit was tested using the best fit model resulting from the inclusion of 30,90, 171, and 221 nodes. Each increase in model parameterization resulted in a significant difference between models as measured at a $5 \%$ significance level.

A difficulty arising from an increased number of spatial nodes is lower calculated resolution values. The 30 -node model with lower damping used to construct model 90 maintained resolution values greater than 0.5 for all nodes above $12 \mathrm{~km}$ depth and to depths of $18 \mathrm{~km}$ for central nodes positioned at $100 \mathrm{~km}$. Diagonal elements of the calculated resolution matrix for model 90 are displayed in Figure 7 and contoured in Figure $6 b$. For model 90 , resolution values are above 0.5 for depths shallower than $9 \mathrm{~km}$, taper toward the center of the model, and extend to a depth of $15 \mathrm{~km}$ at $150 \mathrm{~km}$. Resolution values below $9 \mathrm{~km}$ decrease rapidly. Resolutions for model 221 again illustrate the decay of resolution inherent in continued decrease of velocity node intervals. Resolutions decrease below 0.5 for depths below $7.5 \mathrm{~km}$ tapering from the center and toward the sides of the model. Further decrease in horizontal node spacing rapidly deteriorates resolution.

Another indication of resolution is the ability of the inversion to resolve a perturbation of one velocity node in areas of the model with good ray coverage. A node in model 90 positioned horizontally at 50 and $6 \mathrm{~km}$ vertically was perturbed $+0.1 \mathrm{~km} / \mathrm{s}$ and then inverted for with the same ray geometry as model 90 . This node has a resolution of $\mathbf{0 . 8 2}$ for model $\mathbf{9 0}$. In Figure 11, the inverted delta velocity model is contoured indicating the fidelity of the inversion. Ninety-two percent of the perturbed node is retumed to the proper node position. The image is most

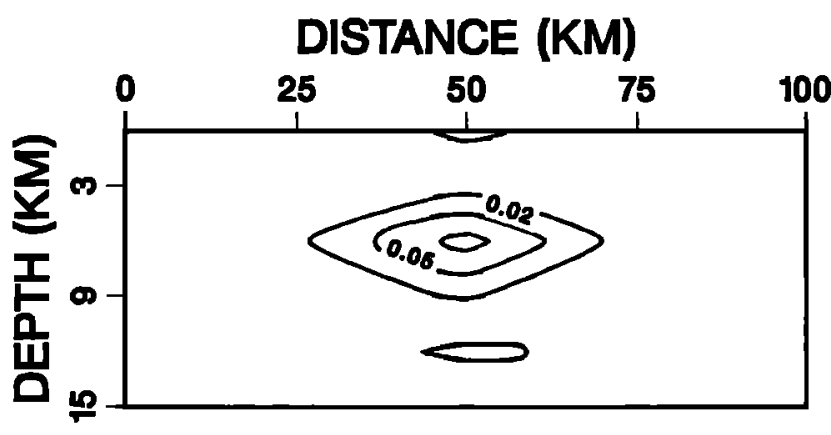

Fig. 11. Contour diagram of resolution of one node at $50 \mathrm{~km}$ horizontally and $6 \mathrm{~km}$ depth perturbed by $0.1 \mathrm{~km} / \mathrm{s}$.

diffused vertically with nodes with $\delta v=-0.014 \mathrm{~km} / \mathrm{s}$ at 0 and $12 \mathrm{~km}$ depth.

The decay in resolution of model 90 as indicated by Figures $6 b$ and 7 is also seen in the ray density contoured in Figure 12. This is a hit count of the number of rays falling within a rectangular box centered at a node position of equal area to the grid system used in the inversion. Ray hit count as seen in the ray density diagram decreases dramatically below $9 \mathrm{~km}$ for the northem portion of the model $(0-100 \mathrm{~km})$ and below $13.5 \mathrm{~km}$ for the southern portion of the model. Ray coverage shown in figure 5 matches the tapering of resolution in the center and sides of the model.

Using a stochastic interpretation, a damping value of 0.5 is derived from a normalized data error of 0.025 and an a priori model standard error of $0.05 \mathrm{~km} / \mathrm{s}$. The calculated a posteriori model errors then range between $0.01 \mathrm{~km} / \mathrm{s}$ at the near surface and $0.05 \mathrm{~km} / \mathrm{s}$ at depth. As resolution values decrease with depth, as evidenced by Figures $6 b$ and 7, the a posteriori model covariance increases. The total model error is likely to be higher than this computed error due to approximations in the forward model specification. The final RMS travel time error of 0.045 , for model 221 , is within the range of estimated data error indicating the resolution of model features as currently parameterized has reached the limitations of the inversion process.

Model features of models 90 and 221 may be correlated with surface geology, well information, and the COCORP Ouachita Mountain reflection line. A schematic of these correlations is displayed in Figure 13a with model 221 in Figure $13 b$ for comparison. The Ouachita COCORP reflection profile extends to $45 \mathrm{~km}$ from the northern end of the PASSCAL profile. From their surface geologic correlations of reflectors, the Stanley Shale, which is a Carboniferous flysch, outcrops from approximately the northernmost PASSCAL station south to 25

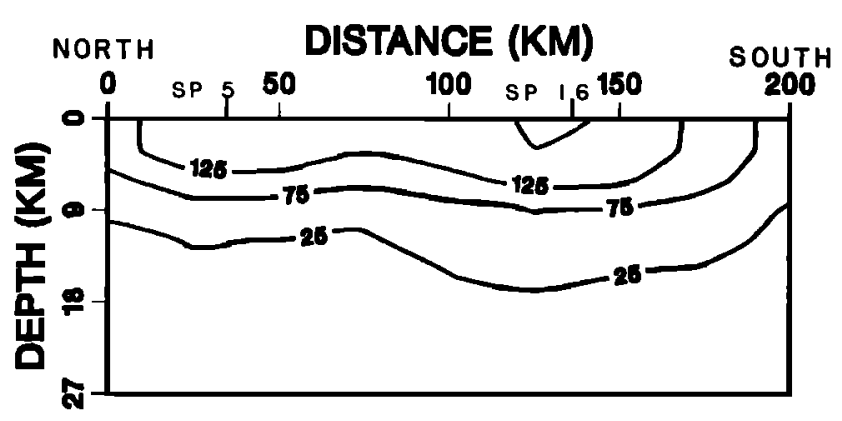

Fig. 12. Ray density or hit count per node for inversion model 90 Horizontal and vertical node intervals are 25 and $3 \mathrm{~km}$, respectively. 


\section{GEOLOGIC MODEL}

A

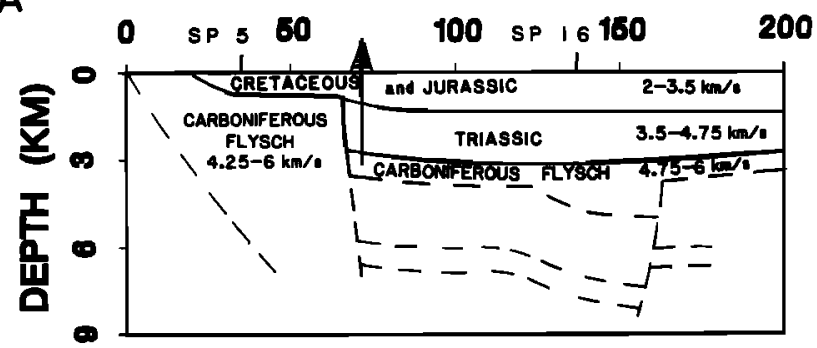

B NORTH

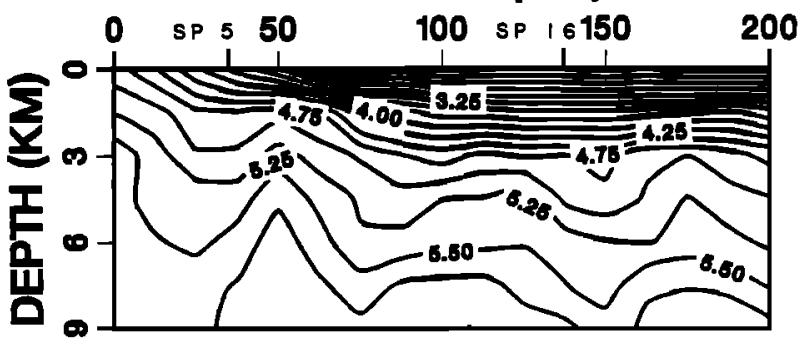

Fig. 13. (a) Schematic geologic cross-section based on geologic and geophysical correlations with model 221 . Correlations are as follows: Cenozoic sediments south of $100 \mathrm{~km}$ with velocities below $2.0 \mathrm{~km} / \mathrm{s}$; Cretaceous and Jurassic sediments with velocities from $2.0 \mathrm{~km} / \mathrm{s}$ to 3.5 $\mathrm{km} / \mathrm{s}$ : Triassic sediments with velocitie from $3.5 \mathrm{~km} / \mathrm{s}$ to $4.75 \mathrm{~km} / \mathrm{s}$; Carboniferous flysch north of the fault with velocities from $4.25 \mathrm{~km} / \mathrm{s}$ to $6.0 \mathrm{~km} / \mathrm{s}$; and Carboniferous flysch south of the fault with velocities from $4.75 \mathrm{~km} / \mathrm{s}$ to $6.0 \mathrm{~km} / \mathrm{s}$. Model features drawn with solid lines are partially correlated with well data. Dashed lines within the Paleozoic sediments indicate fault offset as evidenced by isovelocity lines. (b) Contour diagram of isovelocity lines for model 221 with contour intervals of $0.25 \mathrm{~km} / \mathrm{s}$. Horizontal and vertical node intervals are 12.5 and $1.5 \mathrm{~km}$, respectively.

km. Mesozoic coastal plain sediments outcrop south of $25 \mathrm{~km}$. Cenozoic sediments outcrop south of $90 \mathrm{~km}$. Well information includes depths to geologic units for two wells near the southernmost extent of the COCORP profile and a sonic $\log$ for a well $30 \mathrm{~km}$ east of shot point 11 at $95 \mathrm{~km}$ from the northernmost extent of the PASSCAL experiment.

Woods and Addington [1973] published a NW-SE cross section from well information which interpreted a near vertical Triassic fault north of the Royston well indicated on Figures 2 and $13 a$. The well is positioned approximately $10 \mathrm{~km}$ east of shot point 8 at $65 \mathrm{~km}$. Depths to the top of geologic units allow further geologic association of isovelocity lines. The top of the Carboniferous flysch is at $3.0 \mathrm{~km}$ depth. Another well, the Exxon Harris well, just northwest of the end of the COCORP line, encounters Carboniferous flysch at a depth of approximately $1 \mathrm{~km}$ indicating an offset of $2.0 \mathrm{~km}$. Approximately $2 \mathrm{~km}$ of Triassic red bed sediments fill the faulted graben structure capped unconformably with Cretaceous sediments. The change of depth, seen most clearly on the 4.75 $\mathrm{km} / \mathrm{s}$ isovelocity line and horizontally positioned between 62.5 and $75 \mathrm{~km}$, may be conrelated with Triassic rifting. South of this position, a negative gravity anomaly interpreted to be the signature of Triassic rifting [Kruger and Keller, 1986] intersects the profile.

The upper contact of the Carboniferous flysch may be correlated with velocity on either side of the inferred graben structure. The upper contact of the Carboniferous flysch, identifiable from surface geology and well information, can be correlated approximately with the $4.25 \mathrm{~km} / \mathrm{s}$ isovelocity line north of the Triassic graben structure. In addition, a COCORP reflection interpreted as the top of the Carboniferous flysch when converted to depths using model 221 falls along the 4.25 $\mathrm{km} / \mathrm{s}$ isovelocity line north of $45 \mathrm{~km}$. South of the graben structure, the $4.75 \mathrm{~km} / \mathrm{s}$ isovelocity line is in close agreement with the depth to the top of the Paleozoic.

Geologic units of the Cerboniferous flysch younger than the Stanley Shale are unconformably overlain by Mesozoic sediments south of $25 \mathrm{~km}$. The subsurface extent of the Carboniferous flysch is best indicated by the COCORP interpretation of the lower contact of the flysch with the allocthonous Paleozoic Ouachita facies as an imbricate thrust fault [Lillie et al., 1983]. Below a time of $5 \mathrm{~s}$ on the COCORP reflection profile, a zone of low reflectivity may indicate the maximum depth of the Carboniferous flysch. When converted to depths using model 221 , the lower flysch contact at $0 \mathrm{~km}$ along the PASSCAL profile extends to a depth of $12 \mathrm{~km}$ approximately along the fault drawn as a dashed line from $0 \mathrm{~km}$ in Figure 13a. In addition, this fault correlates with a shallow reflector observable on the stacked reflection profile of the PASSCAL Ouachita data [Plappert, 1988]. The Carboniferous flysch has an estimated thickness between 7.5 and $12.5 \mathrm{~km}$ [Graham et al., 1975]. These correlations suggest the Carboniferous flysch may extend to a depth of at least $12 \mathrm{~km}$. The Paleozoic Ouachita facies which is several kilometers thick [Graham et al., 1975] exists below and north of the thrust fault indicated in Figure 13a.

On the basis of these geologic and geophysical correlations and model estimation of changes in velocity gradient, velocities may be associated with geologic units. Surface velocities in model 221 range between 1.8 and $2.0 \mathrm{~km} / \mathrm{s}$ for the southern half of the PASSCAL experiment correlating with the surface outcropping of Cenozoic sediments. Between 75 and $200 \mathrm{~km}$ at depths of $0-1.5 \mathrm{~km}$ Cretaceous and Jurassic sediment velocities range from 2.0 to $3.5 \mathrm{~km} / \mathrm{s}$. Triassic rift sediments localized between 75 and $200 \mathrm{~km}$, and depths of $1.5-3 \mathrm{~km}$ are imaged by velocities between 3.5 and $4.75 \mathrm{~km} / \mathrm{s}$. North of the possible fault structure between 62.5 and $75 \mathrm{~km}$, velocities between 4.25 and $6.0 \mathrm{~km} / \mathrm{s}$ are correlative with the Carboniferous flysch. South of the possible fault structure, the correlative velocities range between 4.75 and $6.0 \mathrm{~km} / \mathrm{s}$. The Paleozoic Ouachita facies may be correlative with velocities between 6.0 and $6.5 \mathrm{~km} / \mathrm{s}$ at depths greater than $12 \mathrm{~km}$.

The existence of sonic $\log$ data for a well located $30 \mathrm{~km}$ east of shot point 11 at $95 \mathrm{~km}$ from the northem end of the PASSCAL experiment allows comparison with velocity gradients for model 221 to a depth of $4.0 \mathrm{~km}$ (Chevron Oil Company; Cabe Land Company well Et Al 1, Arkansas). Velocities were determined at $0.1-\mathrm{km}$ depth intervals from the sonic log. Velocity gradients are in close agreement for depths below $1.5 \mathrm{~km}$. Near surface sonic $\log$ velocities of $1.2 \mathrm{~km} / \mathrm{s}$ for depths less than $0.2 \mathrm{~km}$ yield a larger gradient than that from model 221 between 0 and $1.5 \mathrm{~km}$. Although the sonic $\log$ velocities exhibit more scatter, the agreement in velocities and gradients confirm the inversion model results. These differences are expected due to averaging caused by a $1.5-\mathrm{km}$ vertical velocity node spacing especially for the near surface.

Although the model parameterization has not allowed velocity discontinuities, it is reasonable to interpret depth offset of isovelocity lines as indicators of fault structure, where 
independent geophysical corroboration exists. Two normal faults associated with the Triassic graben structure are schematically drawn in Figure 13a. Fault features not corroborated by well data are dashed. The thrust fault associated with Paleozoic sediments has already been discussed. The normal fault offsetting the Carboniferous flysch at approximately $65 \mathrm{~km}$ is confirmed by nearby well data from the Royston and Harris well and is inferred to extend at depth into the Paleozoic sediments. [Lillie et al., 1983; Woods and Addingtom, 1973]. Its extension is based on offsets between 50 and $75 \mathrm{~km}$ on isovelocity contours greater than $5.0 \mathrm{~km} / \mathrm{s}$. It is geologically reasonable for normal faulting occurring later in geologic time than the allocthonous overthrusting of the Paleozoic sediments to also offset the deeper Paleozoic strata. The interpretation of normal faulting to offset the southern flank of the synclinal feature centered at $150 \mathrm{~km}$ is based on raytrace forward modeling [Jardine, 1988].

Often velocity models are displayed without indication of degrees of confidence for individual model parameters. The calculation of resolution and model errors allow a determination of model reliability. The decay of resolution with depth in Figures $6 b$ and 7 as well as the increase in standard error indicate that confidence in model parameters also decreases with depth. Diagonal elements of the resolution matrix below a value of 0.5 are poorly constrained and are less reliable, even though travel times associated with deeper rays are matched. Model features associated with the Triassic graben structure are above a resolution value of 0.75 and are thus well constrained. Due to the poor sampling and resolution of deeper portions of the model, one must be cautious about drawing tectonic inferences from deeper model structure. Detailed modeling of the lower crust and Moho reflected phases are necessary to further constrain tectonic models.

\section{SUMMARY}

In this paper, a first arrival travel time inversion of the PASSCAL Ouachita data has been performed. Data correlations have been supplemented based on reciprocity relationships in order to delineate possible fault related structures as well as deeper crustal structure. Inversion models which provide the least detail $(100 \mathrm{~km}$ by $3 \mathrm{~km}$ velocity grid) have acceptable model resolution to depths of $18 \mathrm{~km}$. Increased spatial detail via decreased node spacing leads to a decreased calculated resolution of model parameters. Data correlations enhanced by reciprocity information are consistent, lead to plausible velocity models, and match travel time information. Inversion of first arrival travel time data quantitatively models multiple source and receiver geometries and allows statistical estimation of the goodness of fit of model parameters.

Inversion results allow for correlation of geologic units with seismic velocities and image a Paleozoic basin and Triassic rift graben buried beneath Mesozoic and Cenozoic sediments. Normal faulting associated with the Triassic graben and the thrust faulting within the Paleozoic sediments may be correlated between depth offset of isovelocity lines and other geophysical data. Anticlinal and synclinal model features may be related to inferred fault structures. Detailed modeling of lower crustal and Moho reflected phases is necessary in order to further delineate tectonic structure.

\section{APPENDIX}

Since the formula relating resolution to covariance in this paper is not commonly used, a review of its derivation and significance based on Tarantola [1987] and Nowack and Lutter [1988b] follows.

Solving the linear forward problem $A m=d$ is equivalent to maximizing the probability density representing a priori information

$$
f(m)=\text { const } \exp (-S(m))
$$

where $S(m)$ is the quadratic function

$$
\begin{aligned}
S(m)=1 / 2 & {\left[\left(A m-d_{o b s}\right)^{T} C_{d}^{-1}\left(A m-d_{o b s}\right)\right.} \\
& \left.+\left(m-m_{0}\right)^{T} C_{m}^{-1}\left(m-m_{o}\right)\right]
\end{aligned}
$$

The maximum likelihood inversion minimizes $S(m)$ leading to the solution

$$
<m>=\left(A^{T} C_{d}^{-1} A+C_{m}^{-1}\right)^{-1}\left(A^{T} C_{d}^{-1} d_{o b s}+C_{m}^{-1} m_{0}\right)
$$

Expressing the a posteriori model covariance as

$$
C_{m}^{\prime}=\left(A^{T} C_{d}^{-1} A+C_{m}^{-1}\right)^{-1}
$$

leads to the result that the a posteriori probability density in the model space is Gaussian when the forward problem is linear

$$
f(m)=\text { const } \exp \left(-1 / 2(m-<m>)^{r} C_{m}^{\prime-1}(m-<m>)\right)
$$

The resolution may be expressed in terms of a priori model and data covariance as

$$
R=A_{g}^{-1} A=\left(A^{T} C_{d}^{-1} A+C_{m}^{-1}\right)^{-1} A^{T} C_{d}^{-1} A
$$

The a posteriori covariance may be calculated from the a priori covariance and resolution by the rearrangement of equation (A5) [see Tarantola, 1987]

$$
C_{m}^{\prime}=(I-R) C_{m}
$$

The formula often used to to calculate the a posteriori covariance [Ellsworth and Koyanagi, 1977] is $C_{m}^{\prime}=R(I-R) C_{m}$. In formula (A6), for the a posteriori covariance, $C^{\prime} m$ goes to $C_{m}$ as $R$ goes to 0 .

Acknowledgments. This paper is based on the work of those involved in the planning and implementation of the PASSCAL Ouachita Experiment. This research has been supported by National Science Foundation grants EAR-8518147 and EAR-86-42240/X. Also, Purdue University has supported this research in the form of a David Ross Fellowship. Bill Jardine and John Plappert were responsible for data processing. The authors would like to thank G. Humphries and $C$. Thurber for their careful and constructive reviews.

\section{REFERENCES}

Aki, K., and W.H.K. Lee, Determination of three-dimensional velocity anomalies under a seismic array using first $P$ arrival times from local earthquakes, 1, A homogeneous initial model, J. Geophys. Res., 81, 4381-4399, 1976.

Aki, K., and P.G. Richards, Quantilative Seismology, vol. 2, W.H. Freeman, New York, 1980.

Aki, K., A. Christoffersson, and E. S. Husebye, Determination of the three-dimensional seismic structures of the lithosphere, $J$. Geophys. Res., 82, 277-296, 1976.

Ankeny, L.A., L.W. Braile, and K.H. Olsen, Upper crustal structure beneath the Jemez Mountains volcanic field, New Mexico, determined by three-dimensional simultaneous inversion of seismic refraction and earthquake data, J. Geophys. Res., 91, 6188-6198, 1986.

Banda, E., N. Deichmann, L.W. Braile, and J. Ansorge, Amplitude study of the $P g$ phase, J. Geophys., 53, 153-164, 1982.

Benz, H.M., and R.B. Smith, Simultaneous inversion for lateral velocity variations and hypocenters in the Yellowstone region using earthquake and refraction data, J. Geophys. Res., 89, 1208-1220, 1984.

Bishop, T.N., K.P. Bube, R.T. Cutler, R.T. Langan, P.L. Love, J.R. Resnick, R.T. Shuey, D.A. Spindler, and H.W. Wyld, Tomographic detemination of velocity and depth in laterally varying media, Geophysics, 50, 903-923, 1985. 
Braile, L.W. and R.B. Smith, Guide to the interpretation of crustal refraction profiles, Geophys. J.R. Astron. Soc., 40, 145-176, 1975.

Cerveny, V., I.A. Molotkov, and I. Psencik, Ray Method in Seismology, Vydala, Universita Karlova, Prague, Czechoslovakia, 1977.

Cline, A.K., Scalar- and planar-valued curve fitting using splines under tension, Commun. ACM, 17, 218-223, 1974.

Elbring, G.J., A method for inversion of two-dimensional seismic refraction data with applications to the Snake River plain region of Idaho, Ph. D. thesis, 124 pp., Purdue Univ., West Lafayette, Ind., 1984.

Ellsworth, W.L., and R.Y. Koyanagi, Three-dimensional crust and mantle structure of Kilauea Volcano, Hawaii, J. Geophys. Res., 82, 5379-5394, 1977.

Firbas, P., Inversion of travel time data for laterally heterogeneous velocity structure-linearization approach, Geophys. J. R. Astron. Soc. 67, 189-198, 1981.

Fuchs, K., On the determination of velocity depth distributions of elastic waves from the dynamic characteristics of the reflected wave field, $Z$. Geophys., 36, 531-548, 1970.

Graham, S.A., W.R. Dickinson, and R.V. Ingersoll, Himalayan-Bengal model for flysch dispersal in the Appalachian-Ouachita System, Geol. Soc. Am. Bull., 86, 273-286, 1975.

Healy, J.H., Crustal structure along the coast of Califomia from seismic refraction measurements, J. Geophys. Res., 68, 5777-5787, 1963.

Houseknechh, D.W., and J.A. Kacena, Tectonic and sedimentary evolution of the Atkoma foreland basin, Publ. 1, pp. 3-33, MidContinent Section, Sociezy of Economic Paleontologists and Mineralogists, St. Louis, Mo., 1983.

Huang, H., C. Spencer, and A. Green, A method for inversion of refraction and reflection travel times for laterally varying velocity structures, Bull. Seismol. Soc. Am., 76, 837-846, 1986.

Jardine, W.G., Seismic reflection-refraction study over the southem margin of the Ouachita system of Arkansas and the adjacent Gulf coastal plain, M.S. thesis, 112 Pp., Purdue Univ., West Lafayette, Ind. 1988.

Jordan, T.H., Estimation of the radial variation of seismic velociries and density in the earth, Ph.D. thesis, Calif. Inst. of Technol., Pasadena, 1972.

Kanasewich, E.R., and S.K.L. Chiu, Least-squares inversion of spatial seismic refraction data, Bull. Seismol. Soc. Am., 75, 865-880, 1985.

Keller, G.R., and S.E. Cebull, Plate tectonics and the Ouachita system in Texas, Oklahoma, and Arkansas, Geol. Soc. Am. Bull., 84, 1659-1666, 1973.

Kruger, J.M., and G.R. Keller, Interpretation of crustal structure from regional gravity momalies, Ouachita Mountains area and adjacent Gulf cosstal plain, Am. Assoc. Pet. Geol. Bull., 70, 667-689, 1986.

Lillie, RJ., Tectonically buried continent/ocean boundary, Ouschita Mountains, Arkansas, Geology, 13, 18-21, 1985.

Lillie, R.J., K.D. Nelson, B. de Voogd, J.A. Brewer, J.E. Oliver, LD. Brown S. Kaufman, and G.W. Viele, Crustal structure of Ouachita Mountains, Arkansas: A model based on integration of COCORP refiection profiles and regional geophysical data, Am. Assoc. Pet. Geol. Bull., 67, 907-931, 1983.

Lutter, W.J. and R.L. Nowack, Inversion for crustal structure using reflections from the PASSCAL Ouachita Experiment, J. Geophys. Res., this issue.

Menke,W., Geophysical Dala Analysis: Discrele Inverse Theory, 260 pp., Academic, San Diego, Calif., 1984.

Mooney, W.D., and C. Prodehl, Proceedings of the 1980 Workshop of the IASPEI on the Seismic Modeling of Laterally Varying Structures:
Contributions Based on Data From the 1978 Saudi Arabian Refraction Profile, US. Geol. Surv. Circ., 937, 158 pp., 1984.

Morris, R.C., Sedimentary and tectonic history of the Ouachit Mountains, in Tectonics and Sedimentation, edited by W.R. Dickinson, Spec. Publ. Soc. Econ. Paleontol. Mineral., 22, 120-142, 1974.

Nelson, K.D., R.J. Lillie, B de Voogd, J.A. Brewer, J.E. Oliver, S. Kaufman, L. Brown, and G.W. Viele, COCORP seismic reflection profiling in the Ouachita Mountains of westem Arkansas: Geometry and geologic interpretation, Tectonics, 1, 413-430, 1982.

Nolet, G., Solving or resolving inadequate and noisy tomographic systems, J. Comput. Phys., 61, 463-482, 1985.

Nowack, R.L. and WJ. Lutter, Linearized rays, amplinude and inversion, Pure Appl. Geophys., 128, 401-421 1988a.

Nowack R.L. and WJ. Lutter, A note on the calculation of covariance and resolution, Geophys. J., 95, 205-207, $1988 b$.

Nowack, R.L. and J. Lyslo, Frechet derivatives for curved interfaces in the ray approximation, Geophys. J., 97, 497-509, 1990.

Paige, C.C., and M.A. Saunders, LSQR: An algorithm for sparse linear equations and sparse least squares, ACM Trans. Math. Software, 8, 43-71, 1982.

Pavlis, G.L., and J.R. Booker, The mixed discrele-continuous inverse problem: Application to the simultaneous determination of earthquake hypocenters and velocity structure, J. Geophys. Res., 85, 4801-4810, 1980.

Plappert, J.W., Processing and interpretation of near vertical and wide angle seismic reflection data from the PASSCAL Ouachita Lithospheric Seismic Study, M.S. thesis, 134 pp., Purdue Univ., West Lafayette, Ind., 1988.

Spence, G.D., R.M. Clowes, and R.M. Ellis, Seismic structure across the active subduction zone of Westem Canada, J. Geophys. Res., 90, 6754-6772, 1985.

Steinhart, J. S., and R. P. Meyer, Explosion Studies of Continental Structure, 409 pp., Camegie Institute, Washington, D.C., 1961.

Tarantola, A., Inverse Problem Theory, Elsevier, Amsterdam, 1987.

Thomas, W.A., Strucural and stratigraphic continuity of the Ouachita and Appalachian Mountains, in Symposium on the Geology of the Ouachita Mountains, vol. 1, edited by C.G. Stone, pp. 9-24, Arkansas Geological Commission, Limle Rock, 1977.

Thurber, C. H., Earthquake locations and three-dimensional crustal structure in the Coyote Lake area, central Califomia, J. Geophys. Res., 89, 8226-8236, 1983.

Walper, J.H., Paleozoic tectonics of the southem margin of North America, Trans. Gulf Coast Assoc. Geol. Soc., 29, 230-241, 1977.

Wesson, R.L., Travel time inversion for laterally inhomogeneous crustal velocity models, Bull. Seismol. Soc. Am., 61, 729-746, 1971.

Whittal, K.P., and R.M. Clowes, A simple, efficient method for the calculation of travel times and ray-paths in laterally inhomogeneous media, J. Can. Soc. Explor. Geophys., 15, 21-29, 1979.

Woods, R.D., and J.W. Addington, Pre-Jurassic geologic framework northem Gulf basin, Trans. Gulf Coast Assoc. Geol. Soc., 23, 92-108. 1973.

L.W. Braile, W.J. Lutter, and R.L. Nowack, Department of Earth and Atmospheric Sciences, Purdue University, West Lafayette, IN 47907.

(Received March 8, 1988;

revised November 4, 1988;

accepted April 10, 1989.) 